\title{
An evaluation of commissioning arrangements for intrauterine and subdermal contraception services from general practitioners in London, UK
}

\author{
Richard Ma, ${ }^{1}$ Eleanor Brown ${ }^{2}$
}

\begin{abstract}
${ }^{1}$ General Practitioner (GP), The Village Practice, London; formerly GP Sexual Health Champion, London Sexual Health Programme, NHS London, London; and Doctoral Student, London School of Hygiene and Tropical Medicine, London, UK

${ }^{2}$ Options UK Technical Specialist, Research and Policy, Options Consultancy Services Limited, London, UK
\end{abstract}

\section{Correspondence to} Dr Richard Ma, The Village Practice, London N7 7JJ, UK; richard.ma@btinternet.com

Received 12 November 2013 Revised 8 April 2014 Accepted 4 June 2014 Published Online First 22 July 2014
CrossMark

\footnotetext{
To cite: Ma R, Brown E. J Fam Plann Reprod Health Care 2015;41:54-59.
}

\begin{abstract}
Objectives General practitioners (GPs) in the UK may be commissioned to provide long-acting reversible contraception (LARC), which may have a role in reducing rates of abortion and unintended pregnancies. Primary care trusts (PCTs) in England had commissioning arrangements with GPs to provide LARC but little is known about such contractual arrangements. We studied the commissioning arrangements in some London PCTs to evaluate the cost and clinical governance of these contracts.
\end{abstract}

Methods We requested commissioning contract specifications and activities for intrauterine contraception (IUC) and subdermal implants (SDI) from responsible officers in each PCT in London relating to activities in three financial years, namely 2009/2010 to 2011/2012. We evaluated each contract using a structure, process and outcome approach.

Results Half (15/31) the PCTs responded and submitted 20 contracts used to commission their GPs to provide IUC, SDI or a combination of these with testing for sexually transmitted infections. The information regarding service activity was inadequate and inconsistent so had to be abandoned. Information from 20 contracts suggested there was a variation in clinical governance and quality assurance mechanisms; there was also a range in the reimbursement for IUC insertion ( $f 77.50$ to $f 105.00$ ), SDI insertion ( $£ 25.00$ to $£ 81.31$ ) and SDI removal ( $£ 30.00$ to $\mathrm{f100.00)}$ at 2011 prices.

Conclusion It was not clear from nonresponders if these PCTs had a service in place. Of those that did commission IUC and SDI services, some specifications were lacking in detail regarding aspects of clinical governance. New commissioners should make explicit references to quality and safety criteria as

\section{Key message points}

- Evaluation of contracts supplied by a number of London primary care trusts suggests there was a variation in clinical governance and quality assurance mechanisms.

- There was a range in reimbursement for intrauterine contraceptive insertion (f77.50 to $\mathrm{f105.00),} \mathrm{subdermal}$ implant (SDI) insertion ( $£ 25.00$ to $\mathrm{f} 81.31$ ) and SDI removal ( $\mathrm{f} 30.00$ to f100.00).

- New commissioners should make explicit references to quality and safety criteria as poor-quality specifications can give rise to serious untoward incidents and litigation.

poor-quality specifications can give rise to serious untoward incidents and litigation.

\section{INTRODUCTION}

The UK has a range of contraceptive methods available. Contraception (excluding male and female condoms) is provided free of charge in the UK National Health Service (NHS) from hospitals, general practices and contraception and/or sexual health (CASH) clinics. According to 2008/2009 figures from the Office for National Statistics, $88 \%$ of women 'at risk' of pregnancy were using at least one method of contraception. ${ }^{1}$ The oral contraceptive pill and condom were the most popular methods, used by $38 \%$ and $37 \%$, respectively. Despite this, 
the abortion rate in England and Wales per 1000 women aged $15-44$ years was 16.5 in 2011 , which is double compared to that in 1970 when the rate was 8.0 per 1000 women. $^{2}$

Hormonal contraception and barrier methods can be effective in preventing unplanned pregnancies if used reliably and consistently. In 2005, the then National Institute for Health and Clinical Excellence (NICE) issued clinical guidance on the use of longacting reversible contraception (LARC) in England and Wales. It recommended that women requesting contraception should be given information on all methods of contraception including LARC. It also stated that LARC methods are more cost effective than the combined contraceptive pill, even at 1 year of use. ${ }^{3}$ NICE included copper intrauterine devices (IUDs), the progestogen-releasing intrauterine system (IUS), the progestogen-only injection and the progestogen-only subdermal implant (SDI) in its appraisal. The monthly vaginal ring, which contains both estrogen and progestogen, is also a 'long-acting' method by their definition but as it did not have a UK licence at the time it was not included in the appraisal.

The London Sexual Health Programme (http:// www.londonsexualhealth.org) was set up in 2005 to work on behalf of five London Strategic Health Authorities (SHAs) to lead sexual health commissioning and improve sexual health outcomes in London. It is now defunct following recent NHS reforms. The programme included an initiative to provide support for services to increase the choice and availability of LARC across London. The 'LARC for London' programme was delivered by Options UK, a social enterprise based in the UK (http://www.options.co.uk). The programme recruited one general practitioner (GP) LARC champion for each of the five SHAs in London and a GP Sexual Health Champion (the first author, $\mathrm{RM})$ to provide overall strategic leadership. The 'London LARC Network' also provided support for practitioners and commissioners to increase uptake of LARC by improving capacity through training and education, improving information systems for commissioning, and improving uptake from women through provision of leaflets in different languages.

GPs in the UK NHS have been employed under the 1990 General Medical Services contract that had remained largely unchanged since $1966 .{ }^{4}$ For many women, general practice is a frequently accessed source of contraceptive care and advice. Under the 1990 contract, GPs were financially incentivised to provide contraceptive care including IUD fitting. In 2003, a new GP contract was agreed between the UK government and the British Medical Association. ${ }^{5}$ The new contract comprised a set of core services that GPs are required to provide; there were also 'additional' and 'enhanced' services that go beyond the routine day-to-day care provided by general practice, some of which may require special skills. LARC methods that require training to deliver include IUD, IUS and SDI. These have been included in the 'enhanced' services arrangements which commissioned GPs received extra funding to deliver.

In England, primary care trusts (PCTs) were mandated to commission adequate services for their local populations including enhanced services based on local needs. ${ }^{6}$ A National Enhanced Service (NES) contract for intrauterine contraceptive device fittings was negotiated nationally and a Local Enhanced Service (LES) contract for subdermal contraceptives was developed jointly by the Faculty of Sexual \& Reproductive Healthcare (FSRH), Family Planning Association and Royal College of Nursing for local PCTs to adopt and use. ${ }^{78}$ Although these were available, PCTs were free to develop their own local service specifications and tariff schedules to suit local needs.

Through discussions with local GP LARC champions there was anecdotal evidence of variation in the way GPs were commissioned to deliver intrauterine contraception (IUC - includes both IUD and IUS) and SDI by their PCTs. There appeared to be different commissioning specifications available across London, with different tariffs for each service as well as differences in quality assurance systems. In order to improve the consistency, quality and efficiency of future commissioning of intrauterine and subdermal contraceptive services from GPs in London we decided to survey and evaluate the commissioning arrangements in London PCTs and to describe the activity data delivered using these contracts.

This study did not require ethics approval because it was a service evaluation using non-identifiable data. In addition, the information is held publicly and is available under UK Freedom of Information legislation.

\section{METHODS}

We requested commissioning information regarding IUC and SDI services delivered by general practices from sexual health commissioners in all five SHA sectors in London; this was done in person at commissioners' meetings, via e-mail, and relayed through local GP LARC champions. We also requested activity data for IUC and SDI fittings and removals covered by the contract specifications over the three financial years $2009 / 2010$ to $2011 / 2012$ in order to evaluate the cost per procedure of each contract.

The second author (EB) evaluated each contract using the Donabedian approach of assessing structure, process and outcomes; 9 the assessment criteria are explained in Table 1 and were based on national recommended specifications that were available, including contract models and guidance on best practice. $^{3} 81011$ This evaluation process was validated by 
Table 1 Assessment criteria for London Primary Care Trust Enhanced Service contracts

\begin{tabular}{lll}
\hline Structure & Practitioner criteria & Describes eligibility criteria for health professionals (e.g. evidence of training and competence) \\
& States health care professional has regular CPD \\
& States service has to comply with standards of infection control \\
& States service has adequate facilities for fitting (e.g. speculum, dilators, couch) \\
& States service has adequate resuscitation facilities (e.g. atropine, oxygen) \\
& Other requirements - state \\
Process & States sexual history must be taken and STI tests if appropriate or indicated \\
& States written information must be provided to patient \\
& Provider can produce an adequate record of consultation and procedure \\
& Provider must record type (in case of intrauterine contraception) and batch number of device \\
& States provision of follow up (e.g. after fitting and check-up as and when required) \\
& States procedure for submitting information to PCT for payment \\
& For IUD/IUS fitting \\
& For IUD/IUS check \\
& For contraceptive implant fitting & For contraceptive implant removal \\
& Any other fees/retainers \\
& Other requirements - state \\
& Produce regular audit of fittings - register of patients, device type, complications, follow up \\
& States how PCT will monitor provider (apart from audit and quarterly returns) \\
& States conditions of termination \\
Cutcome & Other requirements - state \\
\hline
\end{tabular}

CPD, continuing professional development; IUD, intrauterine device; IUS, intrauterine system; PCT, primary care trust; STI, sexually transmitted infection.

the first author (RM) using a random sample of five contracts.

Assessments for clinical quality (e.g. audit to assess if individual clinicians or procedures adhered to current best practice), equity, acceptability and appropriateness were outside the scope of this study; some of these assessments would also have required ethical approval to use patient-level data such as demographics and to ask about individual experiences from patients and providers.

We spent 6 months between October 2011 and March 2012 collecting data, with reminders sent at regular intervals during this period. We discussed the findings with GP LARC champions and presented them at a London LARC Conference in March 2012.

\section{RESULTS}

We received 20 discrete contracts for IUC and SDI services from 15 PCTs across the five strategic health authority sectors in London: North Central (Camden, Islington, Barnet), North West (Hounslow), North East (City and Hackney, Tower Hamlets, Newham, Barking and Dagenham), South East (Lambeth, Southwark, Lewisham, Greenwich, Bromley) and South West (Richmond and Twickenham, Kingston). The response rate was $48 \%$ and was lower than expected despite e-mail reminders, reminders at regular commissioners' meetings and also via local GP LARC champions. The results of the contract evaluation are shown in Table 2 and the range of tariffs is given in Table 3.

We had to abandon collection of the activity data because the response rate was poor and the data were inconsistent and inadequate for our purpose. We received responses from six PCTs: one gave aggregate activity and payment information for all GPs rather than per practice and per contract; another gave only implant activity for one financial year; three PCTs returned only IUC data for either one or two financial years; and one returned implant activity for one quarter only. The variation in the way that activity data were presented to us made it difficult to compare across PCTs and different financial years. It was also difficult to request and clarify activity information because information sources were usually in different departments to those of the commissioners.

We found that only one PCT (Islington) used the NES contract for IUC fittings that contained all the criteria for good practice. Some PCTs $(6 / 20$ contracts or $30 \%$ ) bundled services for testing and treating sexually transmitted infections (STIs) (including chlamydia screening), IUC and SDI into one LES contract. Others drew up their own LES contract for each IUC and SDI service. Some of the service contracts referred to national guidance on good practice such as infection control, and guidance produced by NICE and the FSRH.

While most PCTs had contracts that clearly stated governance issues such as safety assurance and practitioner competence, a few were not explicit. Two contracts did not specify eligibility criteria such as practitioner training or competence; five did not mention continuing professional development to maintain knowledge and competence, six did not mention adherence to local infection control standards; and three did not specify equipment for fitting or resuscitation.

We also found that some aspects of good clinical practice were not specified in all the contracts. For example, 65\% (13/20) specified sexual history taking or STI check, $80 \%(16 / 20)$ mentioned giving written information to patients and six contracts did not 
Table 2 Assessment of a sample of London Primary Care Trust Enhanced Service contracts $(n=20)$.

\begin{tabular}{|c|c|c|}
\hline Criteria & $n$ & $\%$ \\
\hline \multicolumn{3}{|l|}{ Structure } \\
\hline Specifies eligibility criteria (e.g. training and competence) & 18 & 90 \\
\hline States health care professional needs regular CPD & 15 & 75 \\
\hline States service has to comply with local standards of infection control & 14 & 70 \\
\hline Specifies required facilities (e.g. fitting equipment) & 17 & 85 \\
\hline Service must have adequate resuscitation facilities (e.g. oxygen, atropine) & 17 & 85 \\
\hline Other criteria & & \\
\hline \multicolumn{3}{|l|}{ Process } \\
\hline Specifies sexual history/STI check as part of risk assessment & 13 & 65 \\
\hline Written information to be given to patient & 16 & 80 \\
\hline States adequate record keeping & 18 & 90 \\
\hline Provider to record type of device (IUD/IUS) fitted & 11 & 55 \\
\hline Provides follow up (e.g. IUD check) & 14 & 70 \\
\hline \multicolumn{3}{|l|}{ Outcome } \\
\hline Specifies audit as a way of monitoring quality and safety & 17 & 85 \\
\hline Specifies how PCT will monitor provider other than audit & 14 & 70 \\
\hline States conditions of termination of contract & 7 & 35 \\
\hline
\end{tabular}

specify that follow-up was required after IUC fitting. Although 90\% stated that adequate record keeping was required, just over half of the contracts required the service provider to record the type of device fitted. Additionally, 17/20 (85\%) contracts specifically indicated audit as a means of assessing quality of clinical service.

There was a three-fold variation in the way GPs were paid for SDI fittings, ranging from $£ 25.00$ to $£ 81.31$ with an average tariff of $£ 44.47$ and median of $£ 42.96$. Similar variation in tariffs for SDI removal was seen ranging from $£ 30.00$ to $£ 100.00$ with an average tariff of $£ 58.05$ and median of $£ 49.52$. There was a narrower range for IUC fittings ranging from $£ 77.50$ to $£ 105.00$ with an average tariff of $£ 83.09$ and median of $£ 81.31$. The payment for an IUC check was fairly consistent, ranging from $£ 20.00$ to

Table 3 Schedule of tariffs for intrauterine device/intrauterine system/contraceptive implant procedures

\begin{tabular}{|c|c|c|}
\hline Procedure & Mean/median tariff & Range \\
\hline IUD/IUS fitting & f83.09/£81.31 & $f 77.50-f 105.00$ \\
\hline IUD/IUS check & f21.39/£21.69 & $f 20.00-f 22.01$ \\
\hline IUD/IUS removal & f44.89/£33.00* & $£ 21.68-£ 80.00^{*}$ \\
\hline Implant fitting & $\mathrm{f} 44.47 / £ 42.96$ & $£ 25.00-f 81.31$ \\
\hline Implant removal & $£ 58.05 / £ 49.52$ & $£ 30.00-£ 100.00$ \\
\hline Other fees & \multicolumn{2}{|c|}{$\begin{array}{l}\text { Some PCTs included fees for testing and } \\
\text { treatment of STIs as part of an enhanced service }\end{array}$} \\
\hline
\end{tabular}

$£ 22.01$ with an average tariff of $£ 21.39$ and median of $£ 21.69$. We found three PCTs that paid for removal of an IUD or IUS: Barking and Dagenham, City and Hackney, and Kingston, paying $£ 21.68, £ 33.00$ and $£ 80.00$, respectively (average $£ 44.89$, median $£ 33.00)$.

\section{DISCUSSION}

From the $48 \%$ response rate we can confidently say that almost half the PCTs in London commissioned IUC and/or SDI services from their GPs. If nonresponders were from PCTs without such contracts, this would suggest that women living in some parts of London had no access to some methods of LARC from their GPs, which meant that local contraceptive and sexual health services might be the sole providers, creating potential problems with capacity and access.

Some general practices might have been commissioned by their PCTs to extend their services to patients registered with other practices in the area; this already happens in the case of minor surgery where a 'host practice' provides services under the Directed Enhanced Service (DES) arrangement for patients belonging to other practices. It was not possible to tell from this study if similar arrangements were in place for IUC and SDI services. This way of commissioning LARC could be considered to help improve access in addition to services from CASH providers as not every GP practice provides IUC or SDI services.

We were not able to obtain all the required information from all the PCTs in the sampling timeframe. At 
that time (Quarters 3 and 4 of the financial year 2011/2012) PCTs were undergoing transition due to NHS reforms; many members of commissioning teams were either no longer in post or had moved to different departments. This might have contributed to the low response rate and difficulties in obtaining the required information such as activity data.

We were disappointed that PCTs were not able to give us accurate activity information under each contract. Contract monitoring and evaluation are part of the commissioning cycle so we expected a system of recording how much individual practices were paid for their performance. ${ }^{12}$ It was difficult to locate key members of PCT staff to obtain the activity data; commissioning departments that managed the contracts for GPs were often different to the departments that processed the activity returns from practices and managed the payments. This also meant the commissioners did not always have the activity data to monitor performance against the contracts. Commissioners should have access to activity data so that they can monitor the performance of providers; it may, however, be a matter of financial probity for another department to manage the payments.

We found that some PCTs used a model of commissioning arrangement whereby STI and contraception were 'bundled' together into a single contract. One PCT provided a rationale for this in the contract specification, in the objective to provide a broader remit of sexual health care from their GPs (which included STI testing and treatment in addition to providing LARC). We support this approach as quite often testing and management of STIs/HIV have been separated from contraception provision; having a 'bundled' contract helps promote holistic sexual health care.

We sought to explain the variation in payment for IUC/SDI fitting and removals. It would seem reasonable for payments to reflect the cost of providing the service, for example, the doctor's and assistant's time, fitting/removal equipment, overhead costs as well as the cost of the device itself. According to the British National Formulary September 2013 edition, the typical cost of devices ranged from $£ 8.95$ for the Copper T $380 \mathrm{~A}^{\circledR}$ IUD to $£ 88.00$ for the Mirena ${ }^{\circledR}$ IUS and $£ 79.46$ for the Nexplanon ${ }^{\circledR}$ contraceptive implant. ${ }^{13}$ GPs are reimbursed separately for IUDs or IUS through the drugs reimbursement system so these costs are not incurred by them. One PCT included the rationale for higher payment for contraceptive implants in the service specification as they are not reimbursed in the same way as IUC, so this was reflected to recoup the cost of implants in the service payment. We had difficulty justifying a tariff of $£ 80.00$ for an IUC removal.

In some PCTs, because there was no local specification for contraceptive implant insertion and removal, some commissioners used an established service specification such as Minor Surgery DES to pay GPs for these procedures. One PCT contract specification mentioned "implant insertion is classified as minor surgery" and reimbursed $£ 43.00$ and $£ 33.00$ for insertion and removal, respectively. Minor Surgery DES has two levels of payment: procedures to remove benign 'lumps and bumps' that require cutting and another for joint injections. The reimbursements were $£ 80.00$ and $£ 40.00$, respectively, at $2003 / 2004$ prices. ${ }^{14}$ Given these points, we did not feel a tariff of $£ 30.00$ fairly reflected the complexity of contraceptive implant removal compared with insertion, especially with the cost of staff time and equipment involved.

The results of this evaluation also showed variation in clinical governance, which may have implications for clinical safety. Two contracts did not stipulate the minimum level of competence required by the health care professional who is commissioned to provide the service. While it was reassuring to see clinical governance issues for safe delivery of services such as practitioner competence, infection control and resuscitation facilities stipulated in many of the contracts, we feel these are essential and should be made explicit in every contract.

Litigation can occur in connection with IUC fittings, and medical defence organisations have warned doctors about the need for good clinical assessment, maintaining competence and adequate note-keeping. ${ }^{15}$ Both the NICE guidance and FSRH guidance on reaccreditation of IUC fitting stipulate a minimal level of activity to maintain competence. ${ }^{3} 10$ They also encourage annual audits to enable practitioners to reflect on the standard of care delivered.

Recent NHS reforms in line with the Health and Social Care Act 2012 have created new commissioning arrangements for services such as STI testing and LARC. ${ }^{16}{ }^{17}$ These services will be commissioned by local authorities from a range of providers such as general practices and 'any qualified providers' such as third-sector and other non-NHS providers. Local authority commissioners may not have experience in commissioning clinical services compared with the PCTs they have replaced. We hope our study will help inform local commissioning arrangements for some aspects of reproductive health, and remind commissioners that it is imperative to have robust clinical and financial governance systems in place.

Local authorities will also need to negotiate with providers a reasonable reimbursement for provision of intrauterine and subdermal contraception. We hope this evaluation will provide a point of reference for local contract negotiations. Because of the need for local negotiations we do not have a 'model' contract to recommend. Guidelines for clinical safety and governance aspects are already available from sources such as NICE and the FSRH. 
Some GP LARC champions were involved to varying degrees in designing these contracts and monitoring activities from practices in their local PCTs. We strongly suggest that future commissioners seek advice from experienced clinicians such as LARC champions, suitably qualified GPs or lead clinicians in CASH services to design the contracts and to be involved in managing the clinical governance. This will ensure that all providers are working to high standards and adhering to current best practice.

\section{STUDY LIMITATIONS}

This evaluation sampled only half the existing PCTs in London. Despite sending out e-mails to the commissioning networks in London and asking at commissioners' meetings for the individuals concerned to respond to our requests, our sampling methods may not have been robust or extensive enough to reach the people holding the relevant information. We could have requested information from local GPs and practice managers who would have agreed and signed some of these contracts and submitted activity data to the responsible officer at their PCTs.

We have not sought to assess the actual practice of the commissioned services as this was outside the remit of this evaluation. This would be helpful in assessing the clinical quality of commissioned services and whether individual practitioners have been adhering to current best practice.

Acknowledgements The authors would like to thank all the commissioners who responded to their requests for information at a difficult time, and the local GP LARC champions for helping with intelligence gathering. They would also like to thank the London Sexual Health Programme for their work on improving access to LARC, and for funding the London LARC Network and the GP champions.

Competing interests None.

Provenance and peer review Not commissioned; externally peer reviewed.

\section{REFERENCES}

1 Office for National Statistics. Opinions Survey Report No. 41. Contraception and Sexual Health 2008/09. London, UK: The Information Centre for Health and Social Care, 2009.

2 Office for National Statistics. Abortion Statistics, England and Wales: 2012. London, UK: Department of Health, 2013.

3 National Institute for Health and Clinical Excellence (NICE). Long-acting Reversible Contraception. Manchester, UK: NICE, 2005 .
4 National Audit Office. NHS Pay Modernisation: New Contracts for General Practice Services in England. London, UK:

The Stationery Office, 2008.

5 NHS Employers. Investing in General Practice - The New General Medical Services Contract. 2003. http://webarchive. nationalarchives.gov.uk/20130107105354/http://www.dh.gov. uk/prod_consum_dh/groups/dh_digitalassets/@dh/@en/ documents/digitalasset/dh_4071967.pdf [archived].

6 Department of Health. Shifting the Balance of Power Within the NHS. London, UK: Department of Health Publications, 2001.

7 NHS Employers. National Enhanced Service - Intra-uterine Contraceptive Device Fittings. 2003. http://www.gpcwm.org. uk/wp-content/uploads/file/NATIONAL\%20ENHANCED\% 20SERVICES/Intra_uterine_contraceptive_device_fittings_NES. pdf [archived].

8 Faculty of Sexual \& Reproductive Healthcare, Family Planning Association, Royal College of Nursing. Recommended Locally Enhanced Service Framework for Contraceptive Implants. 2004. http://www.fsrh.org/pdfs/Recommended\%20LES\%20for\% 20Implants\%20200403.pdf [accessed 2 June 2014].

9 Donabedian A. The quality of care. How can it be assessed? JAMA 1988;260:1743-1748.

10 Faculty of Sexual \& Reproductive Healthcare. Intranterine Contraception. 2007. http://www.fsrh.org/pdfs/ CEUGuidanceIntrauterineContraceptionNov07.pdf [accessed 2 June 2014].

11 Faculty of Sexual \& Reproductive Healthcare. Progestogen-only Implants. 2008. http://www.fsrh.org/pdfs/archive/CEUGuidance ProgestogenOnlyImplantsApril08.pdf [accessed 2 June 2014].

12 Department of Health. The NHS Contractors' Companion. London, UK: Department of Health, 2003.

13 Joint Formulary Committee. British National Formulary. September 2013. London, UK: BMJ Publishing Group and the Royal Pharmaceutical Society, 2013.

14 NHS Employers. Specification for a Directed Enhanced Service - Minor Surgery. Secondary Specification for a Directed Enhanced Service - Minor Surgery. http://www.gpcwm.org.uk/ wp-content/uploads/file/DIRECTED\%20ENHANCED\% 20SERVICES/Minor_surgery_DES.pdf [accessed 2 June 2014].

15 Medical Defence Union. Be wary of coil complications, MDU warns doctors. 28 May 2012. http://www.themdu.com/ press-centre/press-releases/be-wary-of-coil-complications-mduwarns-doctors [accessed 2 June 2014]

16 Department of Health. Overview of Health and Care Structures - The Health and Social Care Act 2012. 2012. https://www.gov. uk/government/uploads/system/uploads/attachment_data/file/ 138258/A3.-Factsheet-Overview-of-health-and-carestructures-240412.pdf [accessed 2 June 2014].

17 Department of Health. Clinically-led Commissioning: The Health and Social Care Act 2012. 2012. https://www.gov.uk/ government/uploads/system/uploads/attachment_data/file/ 138260/B1.-Factsheet-Clinically-led-commissioning-2404121. pdf [accessed 2 June 2014]. 